http://jmscr.igmpublication.org/home/

ISSN (e)-2347-176x ISSN (p) 2455-0450

crossref DOI: https://dx.doi.org/10.18535/jmscr/v7i12.57

Journal Of Medical Science And Clinical Research

IGM Publication

An Official Publication of IGM Publication

\title{
An Incidental Finding of Foreign Body in Extraction Socket: An Unusual Report of Two Cases
}

\author{
Authors \\ Dr Mayur J Gawande ${ }^{1 *}$, Dr M.K.Gupta ${ }^{2}$, Dr Chandrashekar R Bande ${ }^{3}$, \\ Dr Manu Goel ${ }^{4}$, Dr Akshay Mishra ${ }^{5}$, Dr Aishwarya Kadu ${ }^{6}$, Dr Devika Shrivastava ${ }^{7}$ \\ ${ }^{1}$ Assistant Professor, Dept. Oral \& Maxillofacial Surgery, Swargiya Dadasaheb Kalmegh Smruti Dental College \& \\ Hospital, Wanadongari Road, Hingana, Nagpur- 440016, M.S, India \\ ${ }^{2}$ Professor \& HOD, Dept. Oral \& Maxillofacial Surgery, Swargiya Dadasaheb Kalmegh Smruti Dental College \\ \&Hospital, Wanadongari Road, Hingana, Nagpur- 440016, M.S, India \\ ${ }^{3}$ Professor, Dept. Oral \& Maxillofacial Surgery, Swargiya Dadasaheb Kalmegh Smruti Dental College \& Hospital, \\ Wanadongari Road, Hingana , Nagpur- 440016, M.S, India \\ ${ }^{4}$ Reader, Dept. Oral \& Maxillofacial Surgery, Swargiya Dadasaheb Kalmegh Smruti Dental College \& Hospital, \\ Wanadongari Road, Hingana, Nagpur- 440016, M.S, India \\ ${ }^{5}$ Reader, Dept. Oral \& Maxillofacial Surgery, Swargiya Dadasaheb Kalmegh Smruti Dental College \& Hospital, \\ Wanadongari Road, Hingana , Nagpur- 440016, M.S, India \\ ${ }^{6}$ Senior Lecturer, Dept. Oral \& Maxillofacial Surgery, Swargiya Dadasaheb Kalmegh Smruti Dental College \& \\ Hospital, Wanadongari Road, Hingana , Nagpur- 440016, M.S, India \\ ${ }^{7}$ Post graduate student, Dept. Oral \& Maxillofacial Surgery, Swargiya Dadasaheb Kalmegh Smruti Dental College \& \\ Hospital, Wanadongari Road, Hingana, Nagpur- 440016, M.S, India \\ *Corresponding Author \\ Dr Mayur J Gawande
}

\begin{abstract}
Background: Forgotten or missed foreign bodies are often encountered in the oral cavity. These objects may become a potent source of pain and infection. Though foreign body is a common finding, breakage of surgical instrument is a rare intraoperative complication. Improper handling of a surgical instrument or substandard tools may lead to breakage of the instrument. Moreover sometimes an atypical foreign bodies have not yet been reported. Reporting, two cases of a foreign body, associated with an extraction socket, which was later found to be a broken elevator tip \& grit particle.

Case Presentation: Two different patient were reported to the Department of Oral \& Maxillofacial Surgery at Swargiya Dadasaheb Kalmegh Smruti Dental College \& Hospital, Nagpur with different chief complaints After all required radiographic investigations, it were found that foreign body was found in extraction socket which were retrived successfully.

Conclusion: Dentists must pay attention especially when instruments are used in poorly visible areas. Checkup of instruments and materials is also essential. After surgery using routine postoperative screening radiographs help us in conclusion. Dental Professionals should emphasize while deploying metal instruments with strong force in poorly visible areas. A radiographic evaluation is warranted, when instrument breakage occurs intra-operatively. If an unexpected incidence occurs, the patient must be informed and assured all the measures to manage the complications. Patient should be encouraged to used appropriate instruments or objects (toothbrush, dental floss and tongue cleaner etc other than tooth pics, pins, pencil etc) For cleaning the oral cavity and avoid unusual use of unauthenticated objects to minimize the complications.

Keyword: Extraction Socket, Foreign body, Instrument breakage, Elevator tip, Grit particles
\end{abstract}




\section{Introduction}

Complications can be due to negligence of dental health profession by patient themselves. This can occur by professional negligence like bur, broken instrument, elevators and improper handling of instruments and sub-standard or aged tools and by patient negligence atypical foreign bodies other than dental instruments like quack. Foreign bodies are encountered in the orofacial region. Diagnosis of these cases is made accidentally on radiographic examination or may be associated with pain and sign of inflammation. Their identification and removal from the tissue is necessary ${ }^{[1]}$.

Manufacturer should follow the optimum standards, particularly in the case of dental, medical and surgical instruments which could cause serious injuries to patients. However, alterations in manufacturing technique or ineffective quality control occur and they are employed unknowingly ${ }^{[2]}$.

Piece of elevator or bur can be oxidized. The oxidization could be one of the main reasons of the pain and infection. Foreign bodies are considered a misadventure and are associated with several legal problems. Their identification and removal is often necessary ${ }^{[3]}$.

Foreign bodies other than dental instrument used in minor oral surgical procedures to elevate the tooth or root from its socket. Alveolar bone fracture and luxation of the adjacent tooth are common complication associated with their use. In literature, breakage of surgical instruments is an uncommon intra-operative complication as compared to broken endodontic instruments.

The aim of this article to present an unusual two cases of a retained foreign bodies from extraction socket of left mandibular molar region.

\section{Case 1}

A 60 year-old male patient reported to the Department of Oral \& Maxillofacial Surgery at Swargiya Dadasaheb Kalmegh Smruti Dental College \& Hospital, Nagpur with chief complaint of missing teeth in lower left back region of jaw and wants to replace it. Clinical picture shows bluish-black discoloration in regions of lower left first molar region (Figure 1). The routine IOPA radiograph was evaluated, well-defined radiopaque 2 foreign bodies were detected, which were associated with mandibular first molar region (Figure 2). Patient was operated under local anesthesia. Crestal incision was placed at 46 region and a releasing incision was placed on mesiobuccal line angle of 47. Muco-periosteal flap was raised exposing the healed socket. The foreign body along with surrounding blackish discolored tissue was retrieved which was 5 in numbers followed by curettage (Figure:3\&4). After histopathological evaluation (Steriomicroscopic examination) it was confirmed various pieces of grit particles (Figure 5).Smoothening of bony margin followed by thorough irrigation was carried out with betadine and normal saline. Flap was repositioned and sutured with 3-0 silk. Patient was kept for follow up and sutures were removed on $7^{\text {th }}$ day postoperatively. The healing was uneventful.

\section{Case 2}

A 35 year old male reported with a chief complaint of diffuse pain in the left mandibular molar region and history of extraction from the same region 3 months back at private dental clinic. The patient had no significant previous medical history. A clinical examination confirmed uneventful healing and satisfactory dental hygiene without any relevant findings. Although, the healing was satisfactory, patient had pain since 2 weeks. The routine IOPA radiograph was evaluated; a triangular radiopaque foreign body was found obliquely with tip directed mesioinferiorly associated with 36 (Figure: 6). Surgery was warranted to retrieve the foreign body under local anaesthesia. A crestal incision was placed extending from distal to $1^{\text {st }}$ molar till mesial to $3^{\text {rd }}$ molar and muco-periosteal flap was raised exposing the healed socket. The foreign body was retrieved by mosquito forcep followed by curettage (Figure: 7). After histopathological 


\section{JMSCR Vol||07||Issue||12||Page 320-325||December}

evaluation (Steriomicroscopic examination) it was confirmed to be a broken tip of a dental elevator (Figure:8). All the post operative protocol and follow up was done as case I the healing was found to be uneventful and painless.

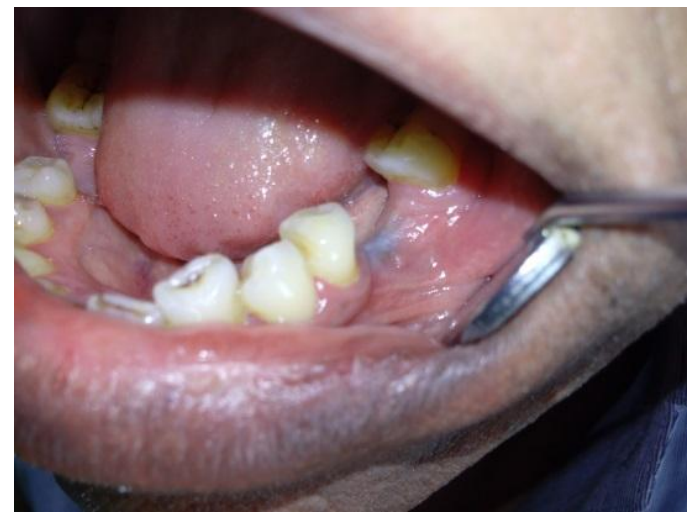

Figure 1Illustrating preoperative picture showing blueish- blackish discoloration

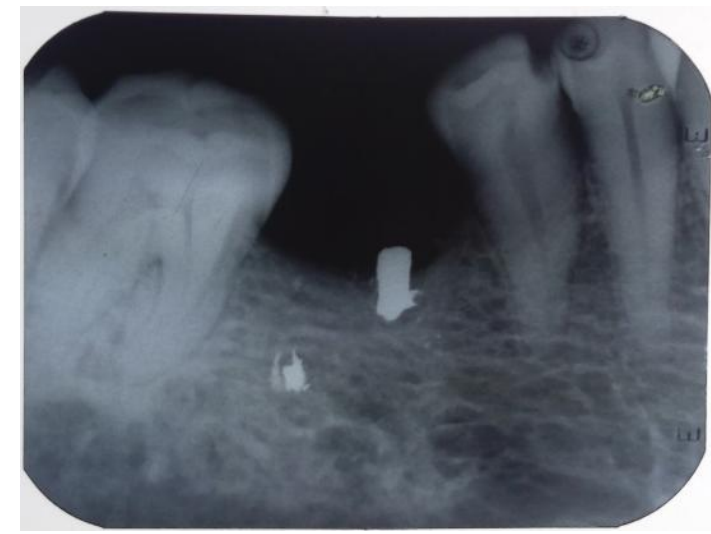

Figure 2 Illustrating IOPA Radio opaque foreign body

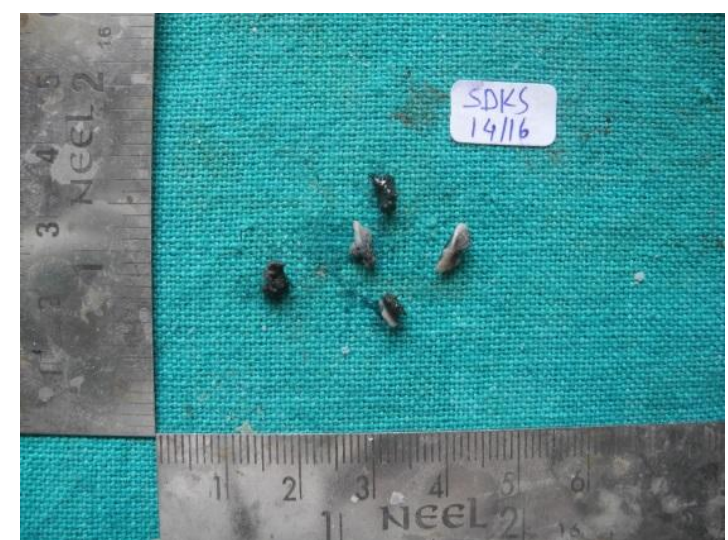

Figure 3 Illustrating Retrived foreign body (grit paricles) with granulation tissue

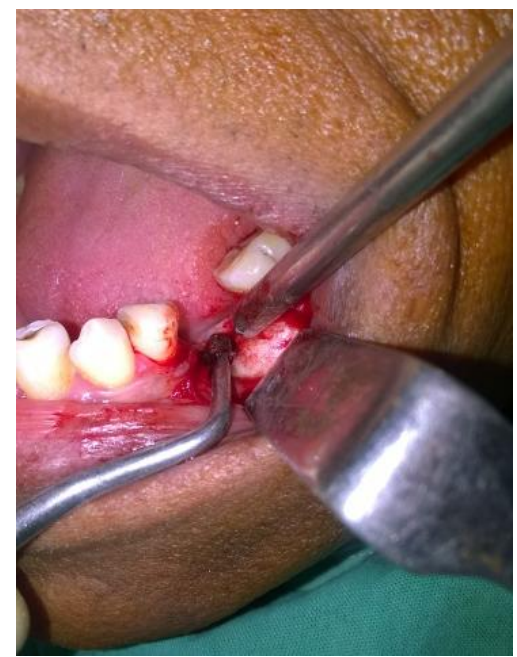

Figure 4 Illustrating retrival of foreign body from the socket

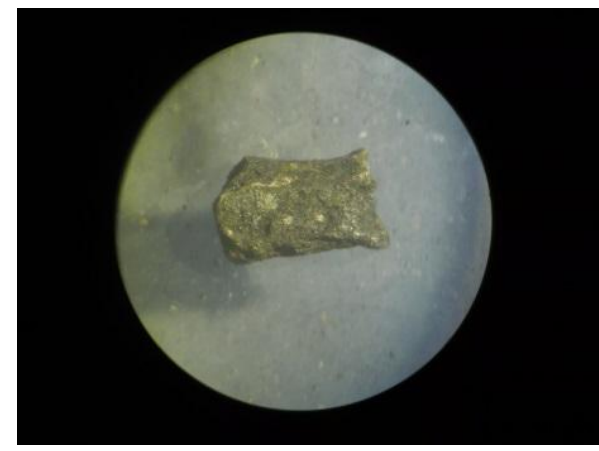

Figure 5 Illustration Steriomicroscopic examinations showing grid particles

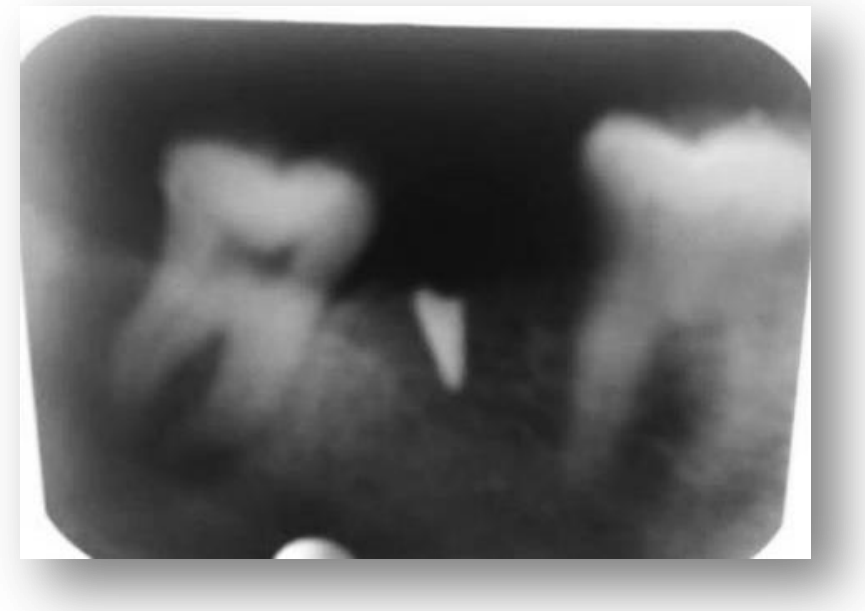

Figure 6: Illustrating IOPA Radio opaque foreign body 


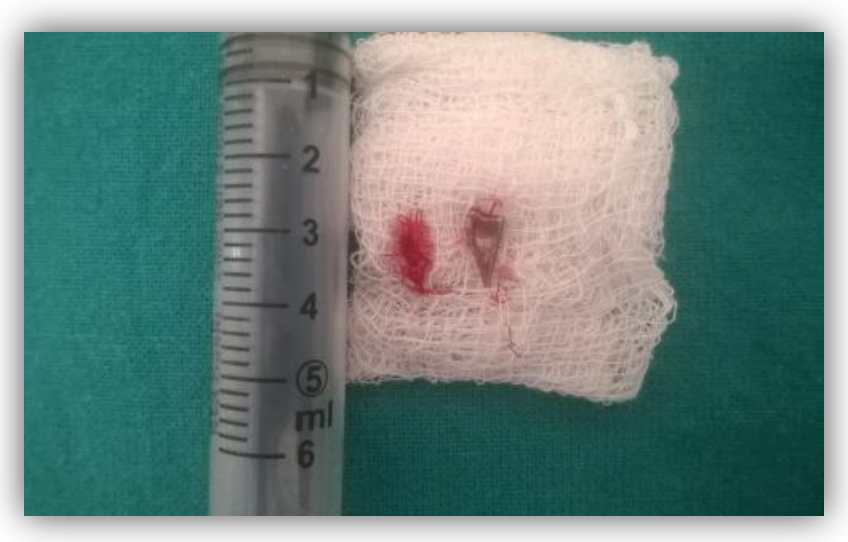

Figure 7 :Illustrating Retrived foreign body (broken elevator tip) with granulation tissue

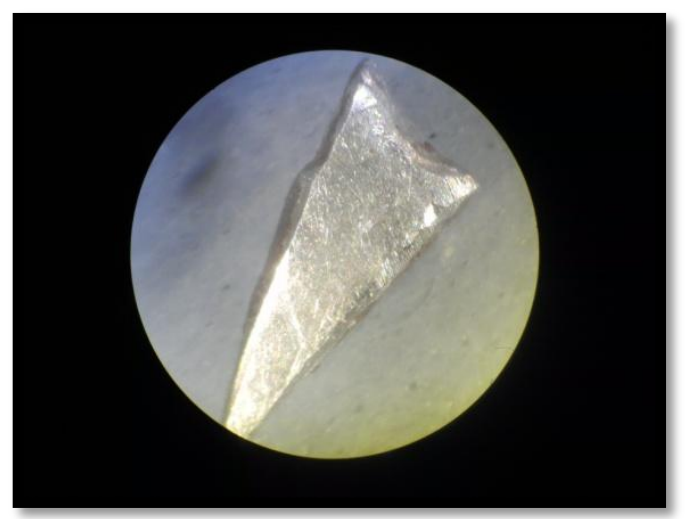

Figure 8: Illustrating showing broken elevator tip.

\section{Discussion}

Any foreign body in extraction socket is likely to cause complication. Surprisingly, here in both the cases socket was healed even after the foreign bodies were still present inside it but there was mild pain in case II. Here with finding, proposing a classification of negligence for the retention of foreign bodies in extraction socket. This can be broadly classified in two groups.

1. Professional Negligence (Role of Doctor and auxillaries)

2 [A]. Self Negligence (Role of patient and relatives)

2 [B] Others (Role of Quacks)

The breakage of instruments, such as endodontic files and dental burs, due to a number of factors including defective manufacturing, stress, fatigue, rust and poor handling is not unknown in Dentistry $^{[4]}$. Professional negligence is regarded as failure to exercise adequate care towards patient if possible in one's professional skills. Negligence from the operator is a grave mistake, which should be avoided and the operators should be updated regarding the medico-legal aspects of it. In this case, such kind of negligence does not even get support from Bolam test in medico-legal consideration $^{[5]}$. Clear, concise and contemporary note with all clinical and radiological data should always be recorded and preserved for any future medico-legal proceedings and clinical follow up.

Few literature have mentioned with the breakage of instruments used for exodontia. Yasuhara et. al. registered various complication of instrument breakage caused by defective surgical instruments over two years. The Authors reported 7 incidences out of 548 operations $^{[6]}$. Kluess et. al. suggested any incident with orthopedic surgical instruments should be reported to the manufacturer and the health authorities for sufficient processing and risk assessment of the complication ${ }^{[7]}$. In case of some reusable metal instruments both titanium alloys and stainless steel (SS) have the high performance range. The SS is the most widely used material for instruments and according to surgical requirements, its alloys vary the most frequent being martensitic and austenitic stainless steels. Biomedical cutting instruments are often made of martensitic stainless steel due to its pronounced durability coupled with acceptable corrosion resistance. Surgical instruments that may be subjected to high pressure forces, such as a dental elevator, is composed of austenitic stainless steel as it is less brittle ${ }^{[8]}$. Surgical instrument manufactures should carry out strict quality controls and have their instruments bear a visible mark as a sign of guarantee. Various authors have suggested that the inferior quality of some surgical instruments may be a reflection of poor working conditions and low standards, particularly in the developing world. Responsibility lies with the suppliers from developed countries manufacturing in the developing world who behave in an unethical manner, maximizing profits and minimizing the remuneration of the people who actually produce the goods ${ }^{[9-10]}$. At present there 
are a number of radiological explorations to identify metallic foreign objects. U. J. Moore et. al. have successfully advocated a metal detector for localization of foreign in the floor of mouth ${ }^{[11]}$. However, a single intraoral periapical radiograph or tube-shift technique may be sufficient. In addition, occlusal radiography can also be employed as necessary. If an occlusal film is not available an intraoral periapical radiograph can be put on occlusally, or on the edentulous crest, and this may reveal an embedded foreign object. Cone beam computerized tomography (CBCT) is an excellent tool to locate metallic foreign objects. It can be used to locate the exact position of foreign body if inaccessible according to routine radiograph techniques ${ }^{[12]}$. After any surgical

\section{Prevention and Management}

\section{Broken Instruments}

\begin{tabular}{|l|}
\hline \multicolumn{3}{|c|}{ Prevention } \\
\hline - $\begin{array}{l}\text { Instruments should be kept dry to avoid } \\
\text { corrosion, which ultimately weakens the } \\
\text { instrument. }\end{array}$ \\
- Standard Autoclave machine should be used for \\
autoclaving. \\
- Strict autoclaving principles should be \\
followed. \\
Quality instruments approved by standardizing \\
bureau of a particular nation should be used. \\
- Instruments should not be repaired or \\
manipulated once any defect is detected. \\
- Substandard or Degraded instruments should \\
not be used. \\
Principles of Elevator must be followed strictly. \\
Uncontrolled force should be avoided. \\
\hline
\end{tabular}

\section{Foreign Body}

\section{PREVENTION}

- Use of dental floss to avoid injuries

- Avoid use of sharp instruments like pen, pencil and / or sticks, in the interdental area procedure the instrument should regularly be monitored for any damage, bending or corrosion to keep a check on its breakage, if found broken, the patient should be informed and it should be located immediately. If not possible to access clinically, the radiographic imaging modalities should be practiced. Sung-Soo Park et. al stated that A dental mini $\mathrm{C}$-arm was beneficial in determining and confining the location of the broken object with intraoperative real-time information, especially for soft tissues. Its small size is adequate for the application of removing foreign bodies in the oral and maxillofacial area and is regarded as a safe and easily controllable device $^{[13]}$.

\section{Management}

- Radiological assessment should be practised using conventional or modern techniques available to ensure the position of foreign body.

- Instrument's working end should be examined after every procedure.

- If observed broken, it should be retrieved immediately followed by curettage.

- On diagnosis at later stage, a surgical removal should be performed under all aseptic precautions.

\section{MANAGEMENT}

- Regular visits to the professionals, twice in a year.

- If any foreign body or food material lodge in between teeth will be removed by appropriate tools 


\section{Conclusion}

Foreign objects should be identified and localized. Plain radiographs are useful to confirm the presence of foreign body, determine the location, assess the size and shape of object

To conclude, instrument breakage may be due to fallowing three reasons:

1) Manufacturing Defects

2) Improper instrument care by Auxillaries

3) Neglegence of operator

It is always advisable to use good quality and reliable brands for any instrument. Whenever any retention of a broken metal instrument is suspected an imaging radiological study will indicate its position and help to avoid potential surgical complications. Preoperative and postoperative monitoring of instruments warranted and if any damage found it should be discarded.

This article is just a step forward in reporting negligence by dental professional which would motivate others avoiding such incidences and managing it appropriately. These incidences occur unknowingly as pitfall can happen by human errors.

\section{Acknowledgement}

All the contributing authors have viewed and agreed to the submission.

\section{References}

1. Aregbesola SB, Ugboko VI; Unusual foreign bodies in the orofacial soft tissue spaces: a report of three cases. Niger J Clin Pract, 2013;16(3):381-385.

2. Ruprecht A, Ross A. Location of broken instrument fragments. Journal Can Dental Association. 1981; 47: 245.

3. Aregbesola SB, Ugboko VI; Unusual foreign bodies in the orofacial soft tissue spaces: a report of three cases. Niger J Clin Pract, 2013;16(3):381-385.

4. Pierro VS, de Morais AP, Granado L, Maia LC. An unusual accident during a primary molar extraction. Journal Clinical Pediatric Dentistry. 2010; 34: 193-5.

5. Prateek R. Bolam test. Journal International Association Forensic Medicine 2007; 29: 1.

6. Yasuhara H, Fukatsu $\mathrm{K}$, Komatsu $\mathrm{T}$, Obayashi T, Saito Y, Uetera Y. Prevention of medical accidents caused by defective surgical instruments. Surgery. 2012; 151: 153-61.

7. Kluess D, Zenk K, Mittelmeier W. Reportable incidents with surgical instruments in orthopedic surgery. Orthopade. 2014; 43: 561-7.

8. Nelson CA. Material selection indices for design of surgical instruments with long tubular shafts. Journal Medicine Engineering Technology. 2013; 37: 102-8.

9. Brophy T, Srodon PD, Briggs C, Barry P, Steatham J, Birch MJ. Quality of surgical instruments. Annals Research Colege Surgery England. 2006; 88: 390-3.

10. Buttha MF. Quality of surgical instruments. Annals Research Colege Surgery England. 2007; 89: 190-2.

11. U.J. Moore, K. Fanibunda, M.J. Gross. Brtish journal of oral and maxillofacial surgery 1993; 31.191-92

12. Eggers G, Welzel T, Mukhamadiev D, Wörtche R, Hassfeld S, Mühling J. X-raybased volumetric imaging of foreign bodies: a comparison of computed tomography and digital volume tomography. Journal Oral Maxillofac Surgery. 2007; 65: 1880-5.

13. Sung-Soo Park, Hoon-Joo Yang, Ui-Lyong Lee, Min-Su Kwon ,Myung-Jin Kim , JongHo Lee ,Soon-Jung Hwang The clinical application of the dental mini $\mathrm{C}$-arm for the removal of broken instruments in soft and hard tissue in the oral and maxillofacial area: .Journal of Cranio-Maxillo-Facial Surgery 40 (2012) 572-578. 